\title{
Swiss Alpine snow pack variability: major patterns and links to local climate and large-scale flow
}

\author{
Simon C. Scherrer ${ }^{1,2, *}$, Christof Appenzeller ${ }^{1}$ \\ ${ }^{1}$ Climate Services, Federal Office of Meteorology and Climatology (MeteoSwiss), Krähbühlstrasse 58, Postfach 514, \\ 8044 Zürich, Switzerland \\ ${ }^{2}$ Climate and Global Dynamics Division, National Center for Atmospheric Research (NCAR), 1850 Table Mesa Drive, \\ Boulder, Colorado 80305, USA
}

\begin{abstract}
The major patterns of interannual Swiss Alpine snow pack variability were determined and their relation to local and large-scale climate variability and recent trends was investigated. The snow variables considered were the seasonally averaged new snow sum, snow depth and snow days for winter (DJF) in the period 1958-1999. Three major patterns of large-scale snow variability were identified. The first pattern explains $\sim 50 \%$ of total variance and extends over the entire area except the southernmost parts. The second pattern explains $\sim 15 \%$ of total variance and has a dipole structure with a maximum on the northern and a strong minimum on the southern slope of the Alps. The third pattern ( $10 \%$ of total variance) is height dependent with a strong maximum at lowland stations and a minimum at high stations. In contrast to the first and second pattern, the third pattern's time component shows a distinct trend. It is well correlated with the $0^{\circ} \mathrm{C}$ isotherm which increased from $\sim 600 \mathrm{~m}$ a.s.l. in the 1960s to $\sim 900 \mathrm{~m}$ a.s.l. in the late 1990s and could be related to climate change. Variability in the first new snow sum pattern was primarily related to total precipitation anomalies. In contrast, variability in the first snow day pattern was primarily related to temperature anomalies. The dominance of precipitation for new snow sums and the dominance of temperature for snow days is physically consistent with the former being controlled by accumulation only and the latter by accumulation and ablation. The surface pressure anomaly pattern linked to the first new snow sum pattern is centred over southeastern Europe, resembling the Euro-Atlantic blocking pattern. For snow days the corresponding pressure anomaly is shifted further southeastward. The second snow pattern is mainly influenced by an East Atlantic like pattern, whereas only the third (height and temperature dependent) pattern is strongly linked to the North Atlantic Oscillation index.
\end{abstract}

KEY WORDS: Snow · Variability · Trends · Temperature $\cdot$ Precipitation · Large-scale flow · Alps · Switzerland

Resale or republication not permitted without written consent of the publisher

\section{INTRODUCTION}

Alpine snow pack is an important economic factor for Switzerland. Revenues from winter tourism are highly correlated with snow abundance (Elsasser \& Messerli 2001). Snow pack also plays a major role in hydroelectricity production and in shaping mountain ecosystems (Beniston et al. 2003, Gyalistras et al. 2005). As a consequence, interannual and long-term changes in snow accumulation and ablation have a direct and pronounced impact on the socio-economic system in the Alpine region (Abegg 1996).
Strong negative Swiss Alpine snow trends were observed in the late 1980s and 1990s (Laternser \& Schneebeli 2003). Scherrer et al. (2004) showed that these trends can be mainly attributed to local temperature increases and that the precipitation impact is small. To understand the observed and possible future changes, it is crucial to investigate the links between variability and trends of local snow pack, local climate variability and large-scale flow.

In winter, snowfall events are typically triggered by flow from northwesterly direction, often accompanied by a cold front impinging on the northern slopes of the 
Alps (cf. Wanner et al. 2000 for details). On a seasonal time scale numerous studies find strong links between snow pack and flow pattern variability on the continental to hemispheric scale (Gutzler \& Rosen 1992, Frei \& Robinson 1999) but also on a regional scale (Dettinger \& Cayan 1995, Cayan 1996, Clark et al. 1999, McCabe \& Dettinger 2002).

The North Atlantic Oscillation (NAO) is one of the leading modes of large-scale flow variability (e.g. Hurrell 1995). It plays a major role in determining snow pack in Poland and Eastern Europe (Clark et al. 1999, Bednorz 2002). For the Swiss Alps, Beniston (1997) found that Alpine high-pressure episodes are linked with the positive phase of the NAO and accompanied by positive temperature anomalies and below average precipitation, both of which are unfavourable for Swiss Alpine snow accumulation. The influence of the NAO on the decadal trends in the occurrence of atmospheric blocking events was confirmed in a recent study (Scherrer et al. 2006).

The aims of this study were to: (1) determine and present the major patterns of Swiss Alpine seasonal mean snow pack variability (Section 4.1); (2) explore the local relation between seasonal mean temperature, precipitation and different variables of seasonal snow pack (Section 4.2); (3) investigate the influence of large-scale flow patterns on the seasonal snow variability patterns and trends (Section 4.3). In contrast to the study of Scherrer et al. (2004) the focus is entirely on leading country-scale snow patterns, not on individual stations or small-scale regional effects.

\section{DATA}

\subsection{Snow pack}

Daily snow depth and new snow sum measurements from the Federal Office of Meteorology and Climatology (MeteoSwiss) and the Swiss Federal Institute for Snow and Avalanche Research (SLF) were used. The data were collected and compiled by Laternser (2002). Quality-checked December-January-February (DJF) data from Alpine and close foreland stations in the period from 1958-1999 were considered for most parts of the analysis. For comparison with the NAO index the snow dataset was extended back to 1931. In the first years of this dataset the data coverage is substantially lower than for the 1958-1999 period dataset. The year allocated to DJF is the year beginning on January 1 st.

Three seasonal snow variables were computed from the daily data: averaged snow depths (SDEPTH), cumulated new snow sums (NEW_SUM) and the number of snow days (SDAY). Snow days were defined, as in Hantel et al. (2000), as days with snow depth $\geq 5 \mathrm{~cm}$. A seasonal value was computed only if data for all 90(91) days in DJF were available and set to missing values otherwise. Missing values were not filled, since the method used to compute the major patterns of seasonal mean snow variability can deal with missing seasonal values (cf. Section 3). In total 89 new snow sum and 110 snow depth stations were used in the analysis (Fig. 1a). The station altitudes range from
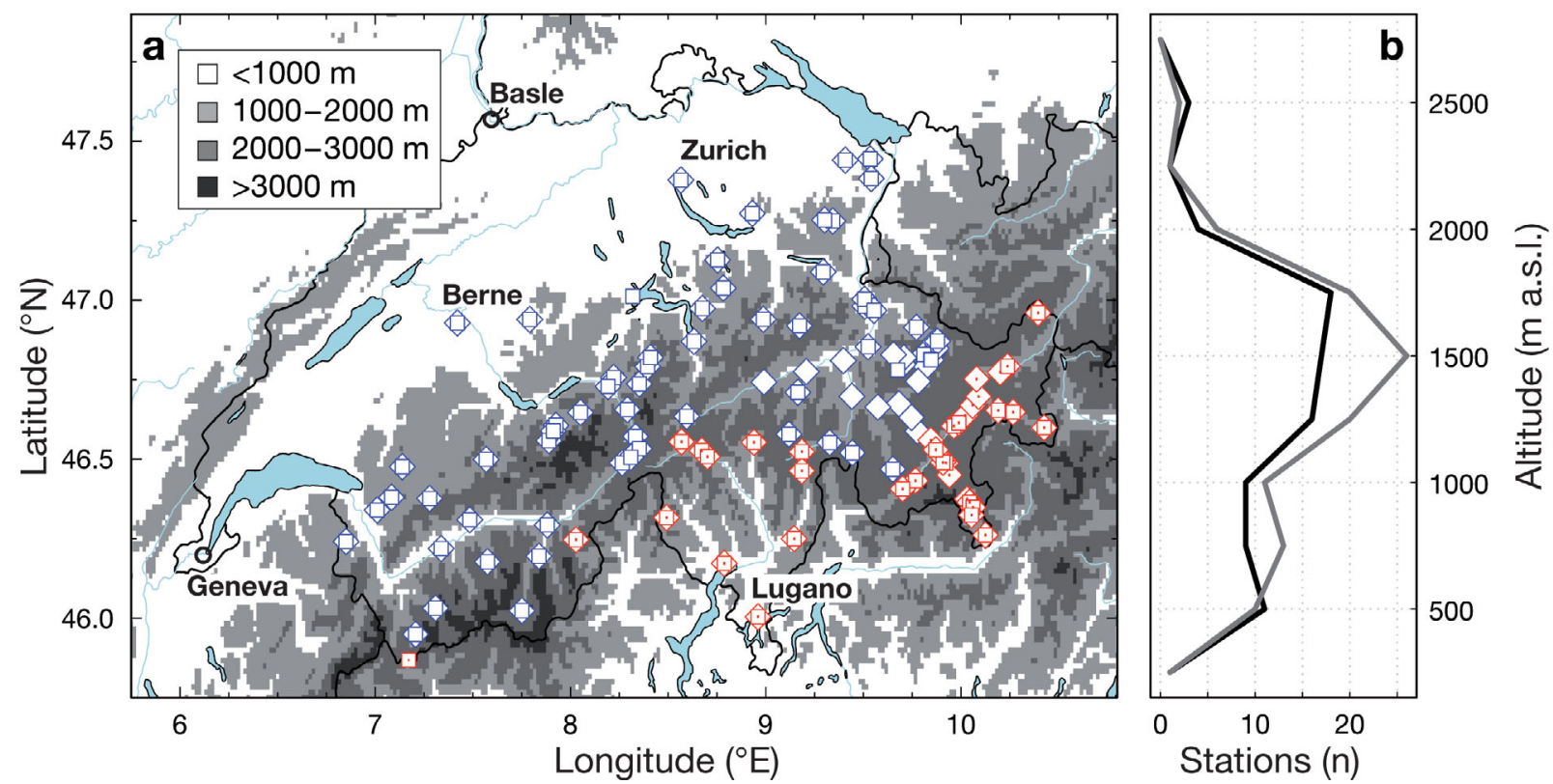

Fig. 1. (a) Location of stations for snow depth (diamonds) and new snow measurement (squares). Stations classified as northern (southern) Swiss are shown in blue (red with a point in the centre). (b) Number of new snow (black line) and snow depth (grey line) stations plotted vs. altitude in $250 \mathrm{~m}$ intervals 
275 to $2540 \mathrm{~m}$ a.s.l. with the highest station density between 1250 and $1750 \mathrm{~m}$ a.s.l. (Fig. 1b). The spatial distribution shows a certain under-representation of very high stations and some clustering of stations along valleys and railway lines (Fig. 1a).

The absolute snow variability in comparison to the mean condition strongly depends on both the snow variable and the altitude. This can be seen in the coefficient of variation $\mathrm{C}_{\mathrm{v}}$ (standard deviation divided by the mean) which is $\sim 0.35$ to $\sim 0.7$ for NEW_SUM, $\sim 0.3$ to $\sim 1$ for SDEPTH and $\sim 0$ to $\sim 0.8$ for SDAY with low values at high altitude stations and high values at low stations. The highest values (up to 1.5) are found for the lowest stations in the southernmost part. Further, especially NEW_SUM measurements are strongly affected by wind advection and air temperature which can result in large errors at individual stations. In this study, however, the focus was exclusively on major larger-scale patterns for which individual station properties are well compensated by our pattern determination procedure (Section 3).

\subsection{Temperature and precipitation}

For most snow measurement sites local temperature and precipitation values are not available. In these cases seasonal mean temperature and precipitation values were linearly interpolated to the snow station coordinates and altitudes using the 5 of 67 (10 of 360) nearest surrounding homogenised Swiss temperature (precipitation) stations from MeteoSwiss as predictors (Scherrer et al. 2004, Begert et al. 2005). The stations chosen for the interpolation are in general close to the snow sites, of comparable altitude and to the first order well representative for the region. The altitude of the seasonal $0^{\circ} \mathrm{C}$ isotherm was determined via a linear regression between seasonal mean temperature values and station altitude.

\subsection{Sea level pressure and early NAO index}

Mean sea level pressure (MSLP) data from the European Centre for Medium-Range Weather forecasts (ECMWF) reanalysis project ERA-40 dataset (Uppala et al. 2005) was used to determine patterns of largescale flow. The domain was the Euro-North Atlantic region from $30^{\circ} \mathrm{N}-80^{\circ} \mathrm{N}$ and $80^{\circ} \mathrm{W}$ eastward to $60^{\circ} \mathrm{E}$. The horizontal resolution of the field was $1^{\circ}$. The seasonal mean values were computed from 6 hourly values. DJF principal component based NAO index values prior to 1958 were provided by the Climate Analysis Section at the National Center for Atmospheric Research (NCAR) (Hurrell 1995).

\section{METHODOLOGY}

Unrotated Principle Component Analysis (PCA) (Preisendorfer 1988) was applied to determine the major patterns of seasonal mean snow variability. The resulting spatial loadings are called Empirical Orthogonal Functions (EOFs) hereafter. The temporal scores are principal components (PCs) below. North's rule of thumb (North et al. 1982) was applied to decide whether an EOF is likely to be subject to large sampling fluctuations and to determine the maximum number of PCs that are well separated from each other.

The fully objective method proposed by Beckers \& Rixen (2003) was used to compute PCA with missing seasonal values. Before application of the PCA procedure, the snow series were standardised in order to circumvent the dominance of high stations caused by much larger absolute anomalies. No further transformation or weighting according to station density in space was performed, since tests showed that this had no substantial influence on the results. As a sign convention for the interpretations, positive values of PCs are defined as positive contributions on the northern slope of the Alps.

PCA was also conducted to determine the major patterns of the local temperature and precipitation at the snow stations and large-scale flow variability (sea level pressure) in the Euro-Atlantic sector (cf. Section 2.1). The large-scale sea level pressure fields were area weighted in order to give similar weights to all geographical regions.

Standard statistical techniques such as Pearson correlation analysis and stepwise multiple linear models were used to relate local variables such as snow, temperature and precipitation with Euro-Atlantic scale flow fields (Junge \& Stephenson 2003). Significance levels (5\% if not mentioned otherwise) were determined using a Monte-Carlo approach of first order auto-regressive (AR1) processes to mimic the redness of the processes investigated.

\section{RESULTS}

\subsection{Major patterns of snow variability}

The PCA of the NEW_SUM, average SDEPTH, and SDAY data yields 3 leading patterns that explain roughly 50,15 and $10 \%$ of the variance, respectively (Table 1). Fig. 2 shows the variance explained by the 8 leading PCs for all 3 snow variables together with an estimation of the eigenvector error (North et al. 1982). The 3 leading NEW_SUM and SDEPTH patterns are well separated and potentially meaningful. For SDAY the second and third patterns are switched 
Table 1. Key data of the 3 leading principal components of Swiss Alpine snow pack. NEW_SUM: new snow sum; SDEPTH: snow depth; SDAY: snow days

\begin{tabular}{|c|c|c|c|c|c|}
\hline \multirow{2}{*}{ Pattern } & \multicolumn{3}{|c|}{ Percentage of explained variance } & \multirow{2}{*}{ Primary } & \multirow[b]{2}{*}{ Secondary } \\
\hline & NEW_SUM & SDEPTH & SDAY & & \\
\hline Uniform & 56 & 51 & 53 & Everywhere except southernmost parts & - \\
\hline North-south & 14.5 & 18 & $10^{\mathrm{a}}$ & Southern Alpine slopes & Northern Alpine slopes \\
\hline Low-high altitude & 7.5 & 9 & $14^{\mathrm{a}}$ & Low altitude stations, esp. in the south & High altitude stations \\
\hline Total & 78 & 78 & 77 & & \\
\hline
\end{tabular}

and not well separated, which is likely related to SDAY saturation with height $\left(\mathrm{C}_{\mathrm{v}} \rightarrow 0\right.$ for altitudes $>1300 \mathrm{~m}$ a.s.l.).

The left panels of Fig. 3 show the spatial patterns of the 3 leading NEW_SUM components expressed as linear correlation coefficient (r) between station series and principal component series. The loadings are all of the same sign and the correlation with the corresponding station based snow series is highly statistically significant (generally $\mathrm{r}>0.7, \mathrm{r}_{\max }=0.95$ ) for all but some southern Alpine stations where $0.24<\mathrm{r}<0.30$. These high correlations show that interannual mid-winter new snow variability can be expressed as either rich or poor snow winters, almost independent of sub-regions. Since the loadings have the same sign at all stations, this pattern is called 'uniform pattern' hereafter. The second pattern discriminates between the northern and southern slopes of the Alpine mountain divide with significantly negative loadings in the south $(-0.83$

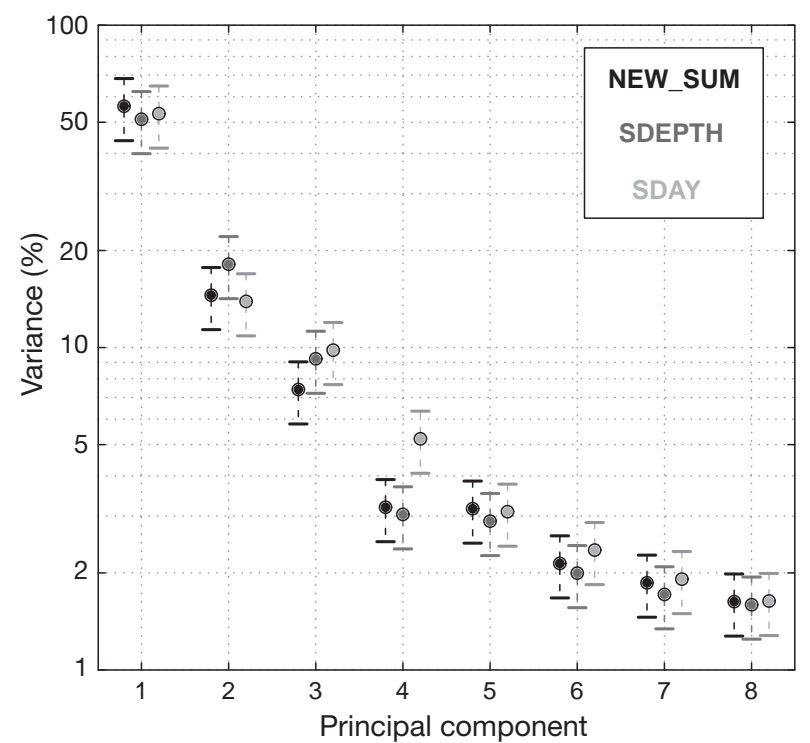

Fig. 2. Percentage of variance explained by the first 8 DJF new snow sum (NEW_SUM), average snow depth (SDEPTH) and snow day (SDAY) principal components. The error bars give the range of uncertainty due to sampling fluctuations using North's rule of thumb (North et al. 1982). The 3 leading components are labelled. The vertical axis has a logarithmic scale $<\mathrm{r}<-0.35$ ) and some significantly positive loadings in the north $(0.32<\mathrm{r}<0.42)$. When this pattern is dominant, sites on the southern slopes tend to have opposite anomalies from those on the northern slopes. This pattern is called 'north-south pattern' hereafter.

The third pattern shows positive and often significant loadings in the low Alpine forelands (north and especially south of main ridge of the Alps, $0.31<\mathrm{r}<$ 0.73 ) and rather small (mostly insignificant) negative loadings in the higher inner Alps $(-0.57<\mathrm{r}<0)$. This pattern is called 'low-high pattern' hereafter. The primary and secondary regions of influence of the 3 leading patterns are summarised in Table 1.

A comparison of the snow patterns with PCA based patterns of an independent precipitation dataset reveals several similarities (Widmann \& Schär 1997, Schmidli et al. 2002). The 2 leading precipitation patterns are very similar to the snow patterns and explain about the same amount of total variance. Yet no direct counterpart in precipitation PCs or precipitation clusters (Baeriswyl \& Rebetez 1997) is found for the low-high snow (i.e. solid precipitation) pattern. The nature of the low-high pattern will be discussed in more detail when the local and large-scale influences are investigated below.

The interannual variability of the leading NEW_ SUM PCs is large. Overall 1958-1999 linear trends are small (cf. Fig. 3, right panels). The most prominent linear trend is found for the low-high components (significant decrease for SDEPTH, $p=0.04$, insignificant decrease for NEW_SUM, $\mathrm{p}=0.21$ ).

The loadings of the uniform pattern can be separated into northern slope and southern slope stations, but there is no clear height dependence (Fig. 4). For the north-south pattern the separation is more pronounced, but again the height dependence is small. A clear negative height dependence is found for the low-high pattern $\left(\mathrm{r}_{\text {corr_coef-altitude }} \approx-0.6\right)$. This is true for both northern as well as southern Swiss stations. The clear height dependence with strong loadings at lower altitudes and the fact that no corresponding pattern is found in the precipitation data makes this pattern a candidate to explore recent snow trends (see below). 

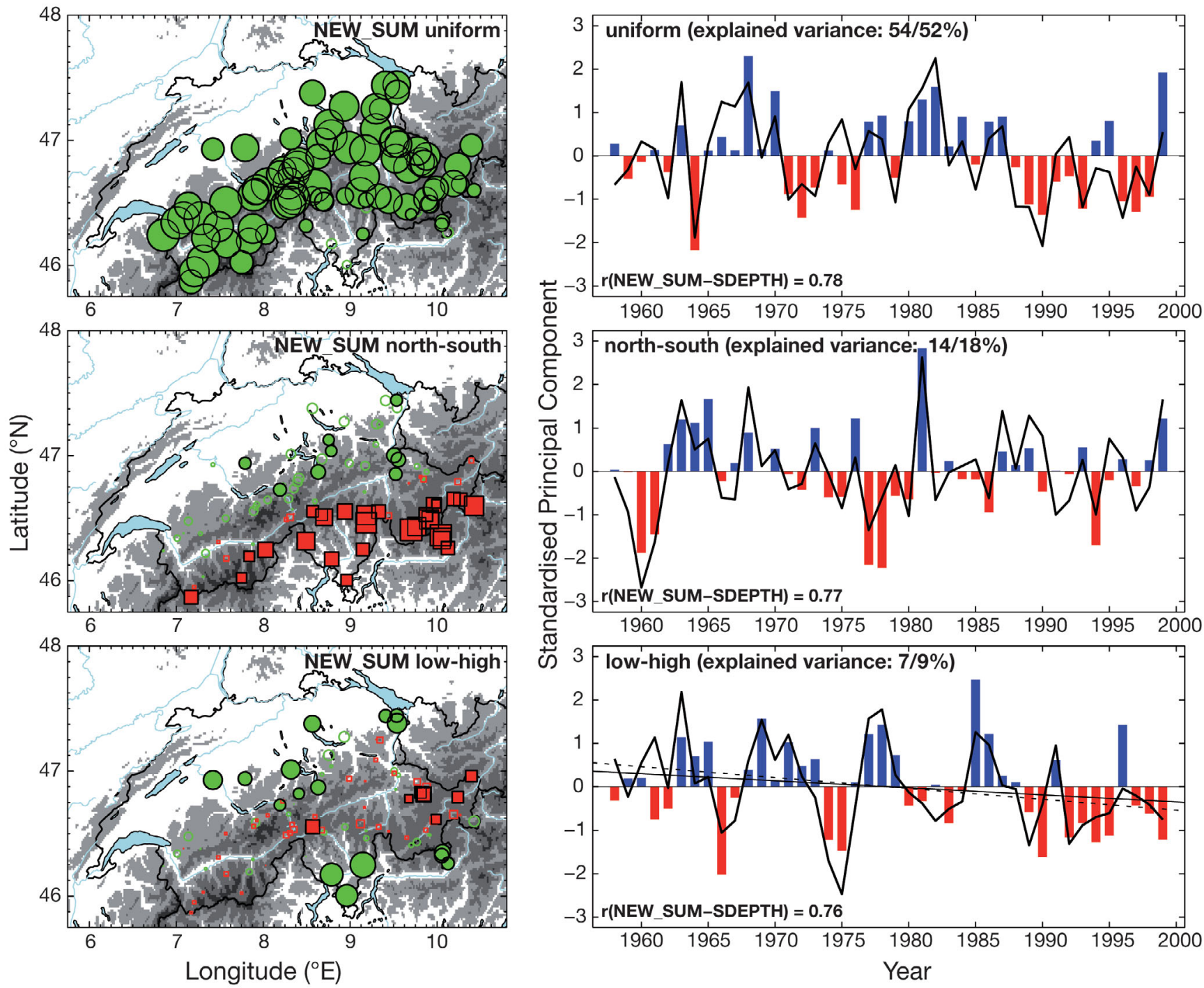

Fig. 3. Left panels: Spatial patterns of the 3 leading principal components of DJF new snow sums (NEW_SUM). Positive correlations of the station series with the principal component series are shown as green circles, negative correlations are shown as red squares. Statistically significant correlation values are filled ( $5 \%$ level). The large (small) symbols in the left panels indicate correlations of $\pm 1( \pm 0.3)$. Right panels: standardised principal component time series of NEW_SUM and snow depth (SDEPTH). The NEW_SUM (SDEPTH) series are shown as colour bar plot (black line). The percentage of explained variance and the correlation coefficient ( $\mathrm{r}$ ) between NEW_SUM and SDEPTH series are also given. For the low vs. high component, NEW_SUM (SDEPTH) linear trend estimations are shown as solid (dashed) line

\subsection{Local temperature, precipitation and snow}

The first principal component of DJF temperature explains $\sim 90 \%$ of the variance in the temperature dataset and is highly representative for all parts of Switzerland (not shown). It is called the 'uniform temperature pattern' subsequently. The second pattern ( $5 \%$ variance explained) shows a (+/-) dipole structure with larger loadings on the southern slopes, and is called the 'north-south temperature pattern' hereafter. The first (uniform) precipitation pattern ( $74 \%$ variance explained) is representative of the northern and central parts of Switzerland. The second (north-south) precipitation pattern ( $~ 9 \%$ variance explained) shows high correlations especially at southern Swiss stations and reversed loadings in the north. The leading temperature and precipitation components are virtually uncorrelated $(\mathrm{r}=$ -0.01) suggesting that several temperature/precipitation winter anomaly combinations are possible (warm-wet, warm-dry, cold-wet and cold-dry winters). 
Table 2. Pearson correlation coefficients (r) of the 3 leading DJF new snow sum (NEW_SUM), snow depth (SDEPTH) and snow day (SDAY) components with the first 2 (uniform and north-south) principal components of temperature (temp) and precipitation (precip). Absolute values $>0.5$ in bold, $0.3-0.5$ in italic. Positive values mean positive correlation with northern Switzerland foreland stations

\begin{tabular}{|c|c|c|c|c|c|c|c|c|c|c|}
\hline \multirow[t]{2}{*}{ Component } & & \multicolumn{3}{|c|}{ Uniform } & \multicolumn{3}{|c|}{ North-south } & \multicolumn{3}{|c|}{ Low-high } \\
\hline & & NEW_SUM & SDEPTH & SDAY & NEW_SUM & SDEPTH & SDAY & NEW_SUM & SDEPTH & SDAY \\
\hline \multirow[t]{2}{*}{ Uniform } & Temp & -0.43 & -0.44 & -0.64 & -0.40 & -0.33 & -0.16 & -0.59 & -0.62 & -0.55 \\
\hline & Precip & 0.76 & 0.46 & 0.28 & -0.17 & 0.12 & 0.09 & -0.40 & -0.10 & -0.08 \\
\hline \multirow[t]{2}{*}{ North-south } & Temp & -0.47 & -0.31 & -0.25 & 0.49 & 0.41 & 0.44 & 0.01 & -0.11 & 0.08 \\
\hline & Precip & -0.10 & -0.17 & -0.17 & -0.80 & -0.62 & -0.70 & 0.33 & 0.38 & 0.14 \\
\hline
\end{tabular}

Table 2 lists correlation coefficients of all snow variables for the 3 leading patterns with the leading 2 temperature and precipitation patterns. The coefficients with the uniform snow pattern strongly depend on the type of snow data. Positive uniform NEW_SUM anomalies are related to both positive uniform precipitation anomalies ( $\mathrm{r}=0.76$, time series in Fig. 5a) and negative uniform temperature anomalies $(r=-0.43)$, but the relation to precipitation is dominating.

Different results are found for the snow variables that measure an integral over processes that accumulate and ablate snow. Positive uniform SDEPTH anomalies significantly correlate with both negative uniform temperature $(\mathrm{r}=-0.44)$ and positive uniform precipitation $(r=0.46)$ anomalies. The positive uniform SDAY anomalies are primarily related to uniform temperature $(r=-0.64$, time series in Fig. 5b) and only weakly related to uniform precipitation $(\mathrm{r}=0.28)$. These numbers show that for SDEPTH and SDAY the temperature influence is important. For SDAY however, the correlation with the uniform temperature pattern clearly dominates over the one with the uniform precipitation pattern.
The interannual variability of the primary snow pattern on the southern Alpine slope (north-south pattern) is highly correlated with the north-south pattern precipitation variability $(-0.80<\mathrm{r}<-0.62)$. This underlines that southern Alpine snow variability is primarily determined by winter precipitation.

The low-high snow pattern shows high negative correlations with the uniform temperature PC ( $\mathrm{r}=$ -0.59 ; Fig. 5c). Temperature increases in recent decades have depleted snow at low altitudes, i.e. precipitation now falls as rain and not as snow. At high altitudes precipitation continues to fall as snow. As a consequence this pattern is found in the snow dataset but not necessarily in the precipitation dataset (compare with results of the previous section). Fig. 6 provides support for this mechanism showing a significant increase of the seasonal $0^{\circ} \mathrm{C}$ isotherm from $\sim 600 \mathrm{~m}$ in the 1960 s to $\sim 900 \mathrm{~m}$ a.s.l. in the $1990 \mathrm{~s}$ ( $\mathrm{p}=0.019$; correlation with low-high snow component: $-0.65 /-0.63$ detrended). To gain further confidence in the mechanism behind the low-high snow pattern it is necessary to investigate its relation to the large-scale flow (see next section).
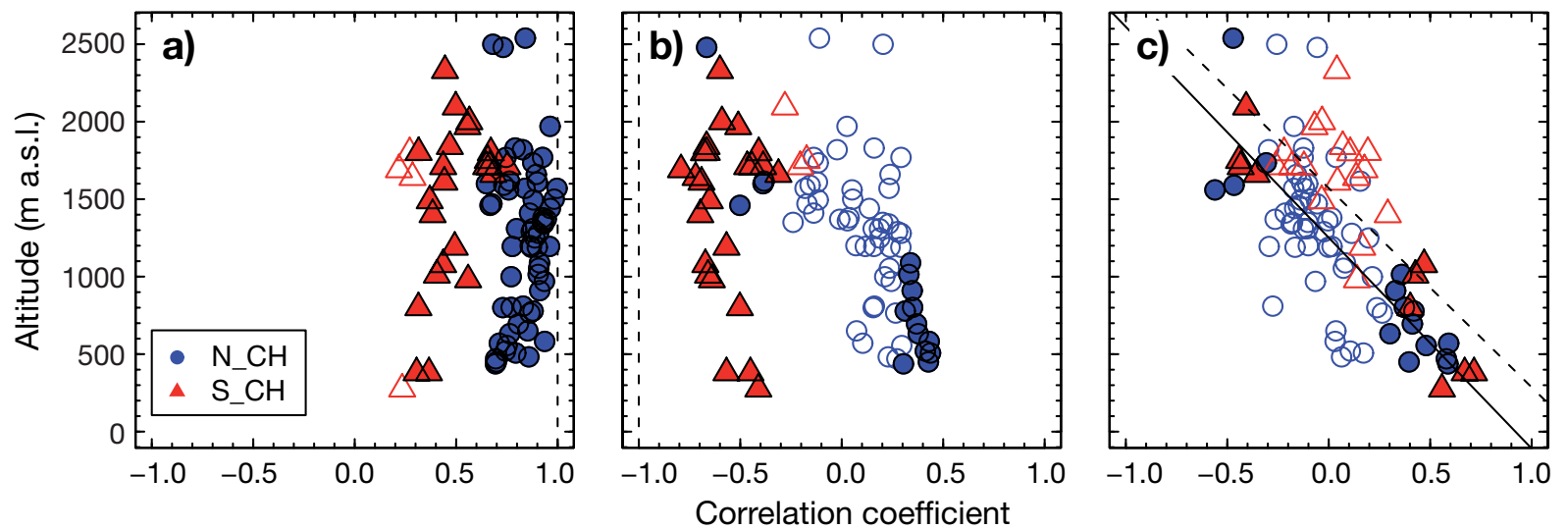

Fig. 4. Correlation coefficients of the NEW_SUM station time series and the loadings of the 3 principal components plotted vs. station elevation. (a) uniform pattern, (b) north-south pattern and (c) low-high pattern. Blue circles (red triangles) denote northern (southern) Swiss stations. Significant (insignificant) coefficients (5\% level) are filled (open). The solid (dashed) line in (c) shows linear fits to the data for the northern (southern) Swiss stations 


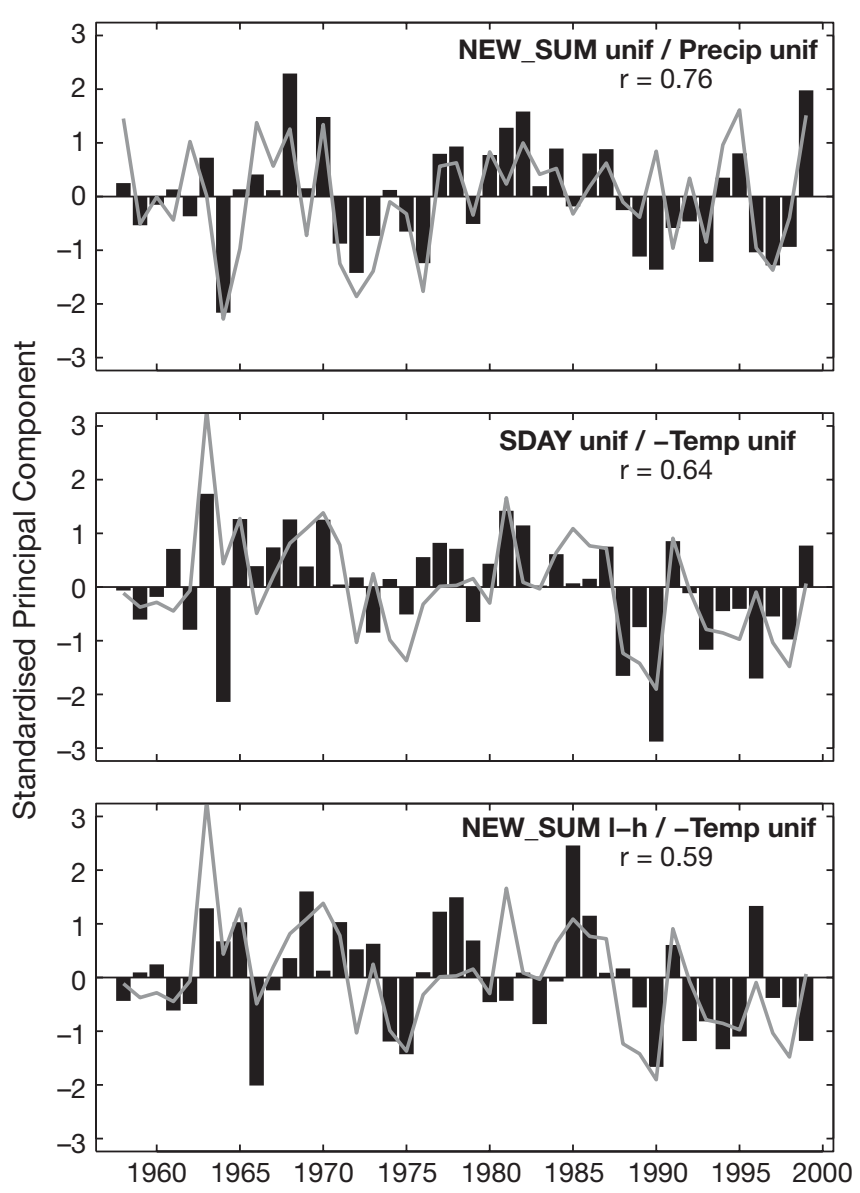

Fig. 5. Standardised time series of selected new snow sum (NEW_SUM) and snow day (SDAY) PCs (bars), and temperature and precipitation PCs (grey lines); unif: uniform, l-h: low-high. For better comparison, the Temp unif series is plotted with switched sign

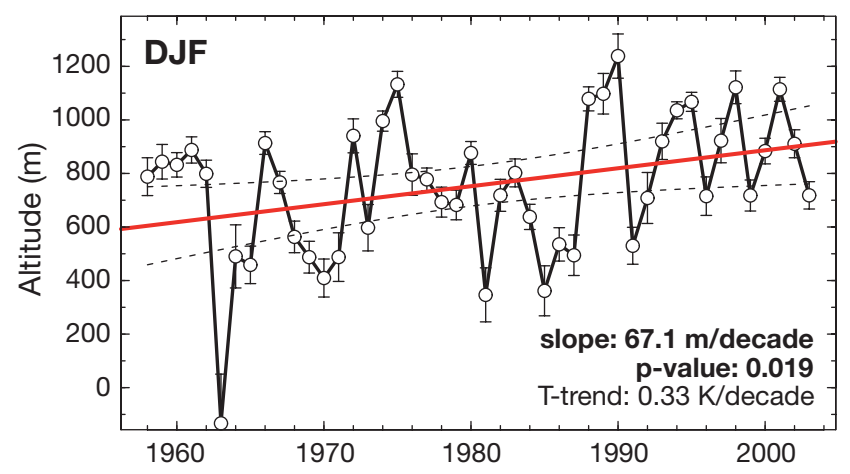

Fig. 6. Elevation of the $0^{\circ} \mathrm{C}$ isotherm for the DJF season in the Swiss Alps 1958-2003 based on 67 homogenised surface series. The red line shows the linear trend estimate, the dashed line represents the $95 \%$ confidence interval for the slope. Error bars depict the 5-95\% confidence interval of the individual year altitude estimates

\subsection{Large-scale flow and local climate variability}

\subsubsection{Relationship between NAO and snow pack}

The direct relation of the state of the NAO to Swiss climate variability is ambiguous and highly dependent on the variable considered (Schär et al. 1998, Appenzeller et al. 2000, 2001, Massacand \& Davies 2001, Schmidli et al. 2002). Fig. 7 shows a scatterplot of DJF NAO index values versus standardised DJF NEW_SUM for the period 1931-1999. In accordance with earlier results (Beniston 1997), the correlation is negative $(r \approx-0.30)$ and significant $(\mathrm{p}=0.04)$. In other words, positive (negative) NAO index values associated with strong (weak) westerlies over northwestern Europe show a tendency to be linked with small (large) NEW_SUM. However, the relation does not hold for extreme NEW_SUM years and extreme seasonal NAO indices. The years 1968 and 1999, both extremely rich in new snow, and the year 1964, which was extremely poor in snow, are accompanied by moderate NAO index values. Also the extreme NAO index years (positive: 1989, negative: 1969) are not extreme snow years.

Fig. 8 shows 31 yr running window correlations of the NAO index with the NEW_SUM PCs for the period 1931-1999. The correlation with the uniform PC is negative, oscillating around the $5 \%$ significance level and is rather constant over the years. Correlation with the north-south PC is positive, shows a weak correlation increase from not statistically significant values at the beginning to slightly significant values at the end

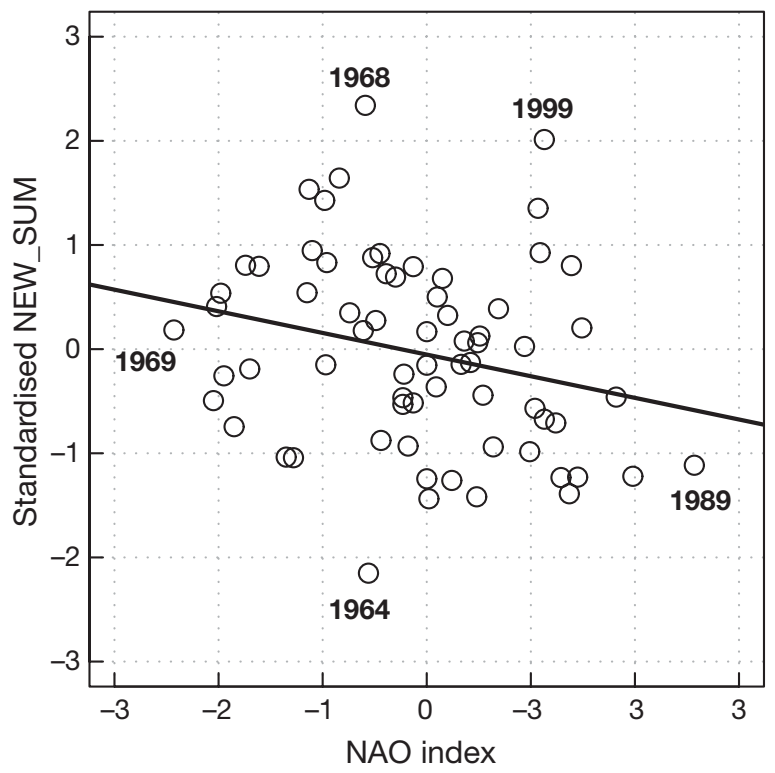

Fig. 7. Scatterplot of DJF NAO index vs. DJF mean standardised new snow sums (NEW_SUM) for 1931-1999. Also shown: linear least square fit and 5 extreme NEW_SUM or extreme $\mathrm{NAO}$ index years 


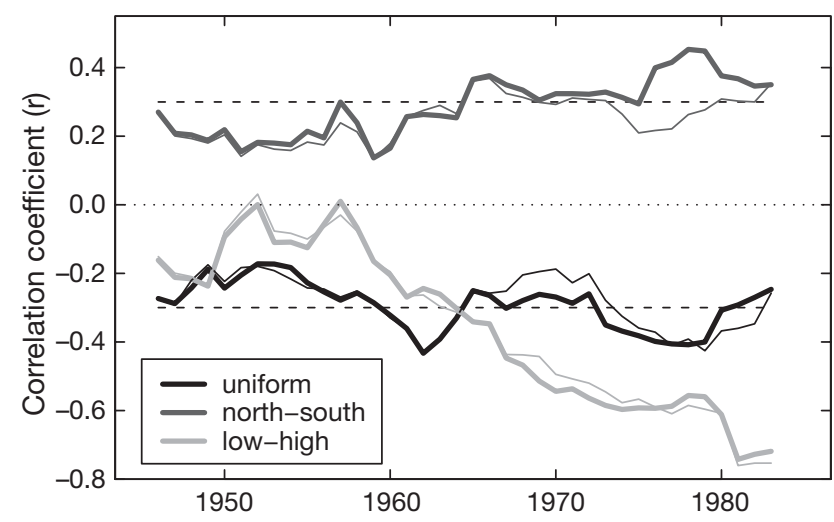

Fig. 8. Correlations (31 yr running window) between DJF NAO index and leading DJF new snow sums PCs for the period 1931-1999. Thick lines: linearly detrended 31 yr windows, thin lines: original data. Dashed lines represent the $5 \%$ significance levels

of the period considered. The low-high PC correlation is not statistically significant at the beginning of the observation period, but starts decreasing in a rather monotonic manner after a while. The maximum correlation is found at the end of the century with values of almost -0.8 . Very similar results are found when the series are detrended (thick lines in Fig. 8) indicating that the high correlations are no artefact of the linear trends in the series. Although the data base for the principal component results in the early period is less certain, it seems that the low-high pattern variability is well related with NAO variability only in the last $40 \mathrm{yr}$ of the 20th century, where the low-high pattern, the NAO index and local temperature all show clear trends. This result is in good agreement with the previous section's hypothesis that the low-high pattern may be the imprint of a rising snow line and with the findings of a pronounced influence of NAO upon recent Swiss snow pack declines (Scherrer et al. 2004).

\subsubsection{Snow patterns and large-scale flow}

Fig. 9 shows grid point based correlation maps of the 3 leading DJF NEW_SUM PCs and the leading SDAY PCs with DJF sea level pressure variability. The uniform NEW_SUM PC (Fig. 9a) is negatively correlated with sea level pressure over central and southeastern Europe $\left(r_{\min } \approx-0.65\right)$. Switzerland lies at the western boundary of the northwest-southeast tilted monopole of enhanced correlation $(\mathrm{r} \approx-0.4)$. In the anomalous low (high) pressure case there is anomalous northwesterly (southerly) flow towards the Alps accompanied by surpluses (deficiencies) of snow. The anomalous lowpressure (i.e. positive NEW_SUM anomaly case) composite 'absolute flow' field (mean $-1 \mathrm{SD}$ ) reveals that the Alpine region is influenced by a strong westerly flow component (not shown). The associated flow is stronger and the incident flow is from more northerly directions than the overall mean flow, which is westsouthwest. Since a westerly component usually is associated with wetter conditions, it is consistent with the finding in Table 2 that the uniform pattern is primarily determined by precipitation and only secondarily by temperature. The anomalous high pressure (i.e. negative NEW_SUM anomaly case) composite is characterised by high pressure directly over the Alpine region, which is part of a ridge stretching from the Azores to Eastern Europe.

The correlation map for the uniform SDAY PC (Fig. 9b) also shows a correlation monopole over southeastern Europe, but in contrast to the uniform NEW_SUM PC, the coefficients are somewhat lower $\left(\mathrm{r}_{\min } \approx-0.55\right)$ and the expansion of high negative correlation to central and northwestern Europe is missing. The Alps now lie at the northern boundary of the region with significantly negative correlation $(\mathrm{r} \approx-0.3)$. The interpretation is therefore slightly different. The low-pressure anomaly over southeastern Europe is accompanied with an additional easterly component towards the Alps (blue arrow). The anomalous low pressure (i.e. positive SDAY anomaly case) composite shows that in this phase westerlies are slightly further in the north and that therefore continental influences (cold air) are somewhat enhanced. This is in agreement with Table 2, where the uniform SDAY pattern is more strongly correlated with temperature than with precipitation. The anomalous high pressure (i.e. negative SDAY anomaly case) composite shows that the Alpine region is determined by high pressure.

The correlation maps for the NEW_SUM and SDAY north-south PC (Fig. 9c,d) are characterised by a monopole of positive correlation $\left(\mathrm{r}_{\max } \approx 0.65\right.$ and 0.55$)$ over the easternmost Atlantic Ocean and the British Isles, similar to a spatial pattern known as East Atlantic pattern (Barnston \& Livezey 1987, Pavan et al. 2000). The positive phase with an additional flow component from northerly directions (blue arrow) is linked with a weak surplus (strong deficiency) of NEW_SUM on the northern (southern) slopes of the Swiss Alps (cf. Fig. 3). The composite field (not shown) shows a ridge of the Azores High reaching the Alps, which is unfavourable for southern Alpine precipitation. The negative phase (additional southwesterly flow component) is characterised by NEW_SUM surpluses (deficiencies) on the southern (northern) slopes. The composite field shows southwesterly flow towards the southern Alpine slopes which is favourable for additional precipitation. These flow situations are in good agreement with the high correlation with local precipitation on the southern slopes (Table 2). 

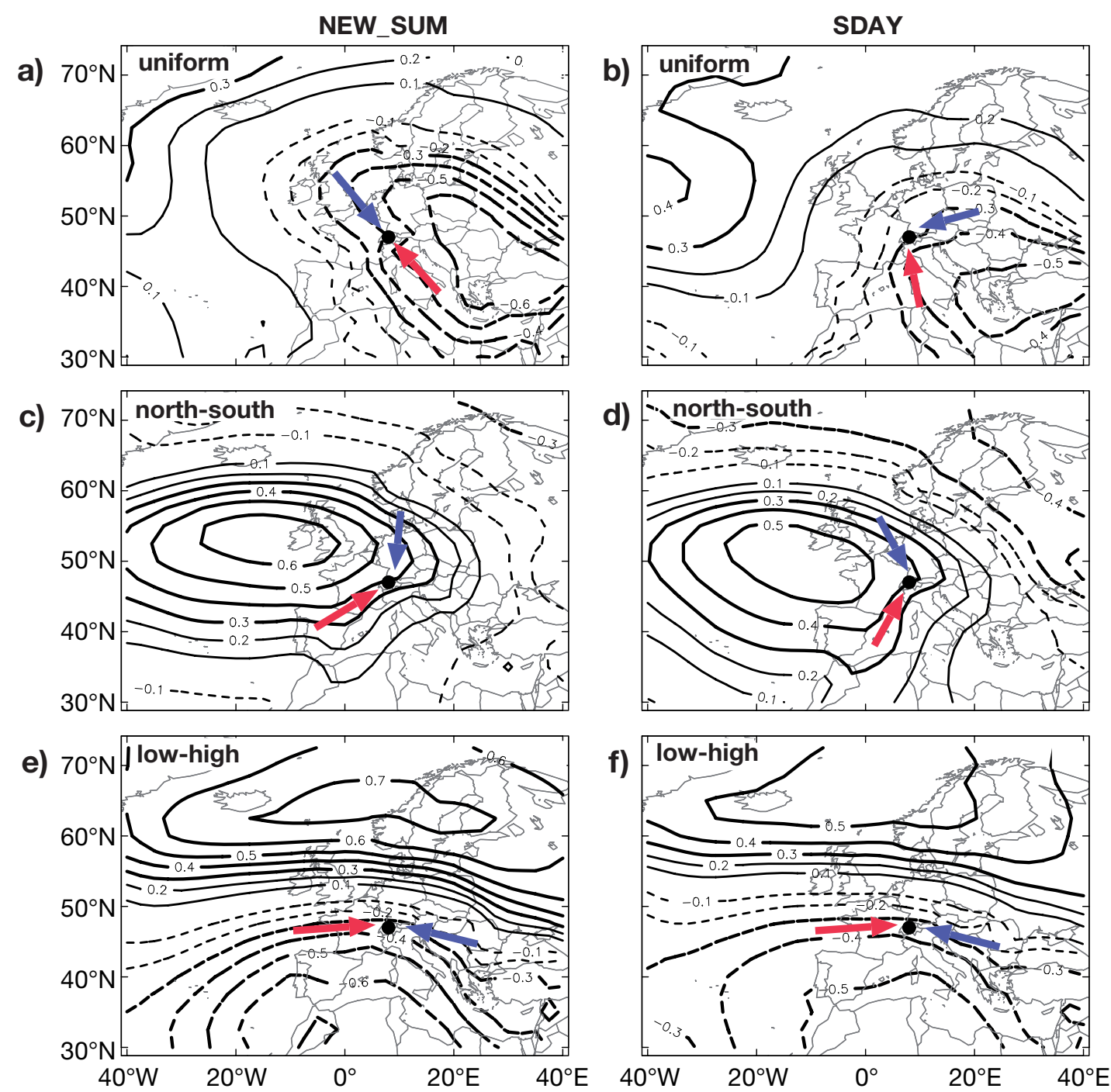

Fig. 9. Correlation map of DJF 1958-1999 sea level pressure and the uniform, north-south and low-high pattern of Swiss Alpine new snow sums (NEW_SUM: a,c,e) and snow days (SDAY: b,d,f). Contours for correlation values $|r| \geq 0.3$ are shown in bold. Contour interval is 0.1, with zero contour omitted. Black dot: Swiss Alps. Colour arrows show the additional geostrophic flow direction (qualitatively only). Blue (red) arrows indicate in $(\mathrm{a}, \mathrm{b})$ more (less) snow in the entire Swiss Alps, (c,d) more (less) snow in northern parts, (e,f) more (less) snow primarily at low altitudes. Positive (negative) anomalies are given by solid (dashed) lines.

The NEW_SUM and SDAY low-high PC correlation maps (Fig. 9e,f) show a dipole pattern with centres over the Norwegian Sea and northwestern Africa which bears some spatial (cf. Fig. 10a) and temporal similarity with a negative NAO phase ( $\left.\mathrm{r}_{\text {(low-high } \mathrm{PC} \text { )-NAO }} \approx 0.6\right)$. The additional westerly flow component in the years with negative (positive) pressure anomalies over northern (southern) Europe is linked with negative (positive) NEW_SUM anomalies at low (some high) altitude stations north as well as south of the main ridge of the Alps. In the reversed case (reduced westerly flow, blue arrow) positive (negative) snow anomalies are found at low (some high) stations. The composite fields show that in the case with signs as in Fig. 9e the Eurasian High is strong. The associated flat pressure distribution in central Europe and flow from southeastern Europe favours cold and dry conditions, in broad agreement with the correlation results in Table 2. In the opposite case there is a ridge spreading from southwestern Europe to the Alps.

Analogous correlation maps are found for the second and third principal component pattern of SDEPTH. Correlation maps based on geopotential height at the $500 \mathrm{hPa}$ level are smoother, but the general interpretations remain the same (not shown). 


\section{a) NAO (49\%)}

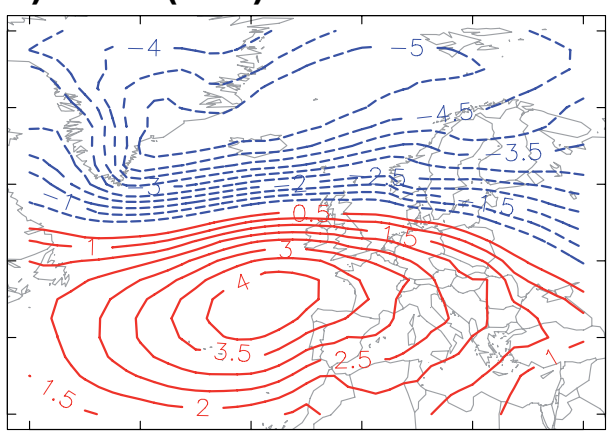

\section{b) $E A(18 \%)$}

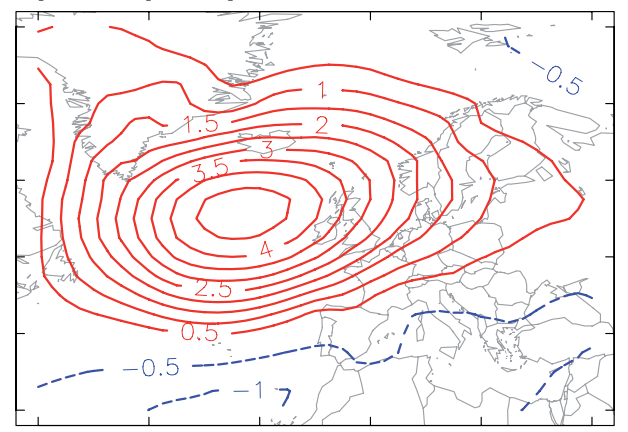

c) BLO (12\%)

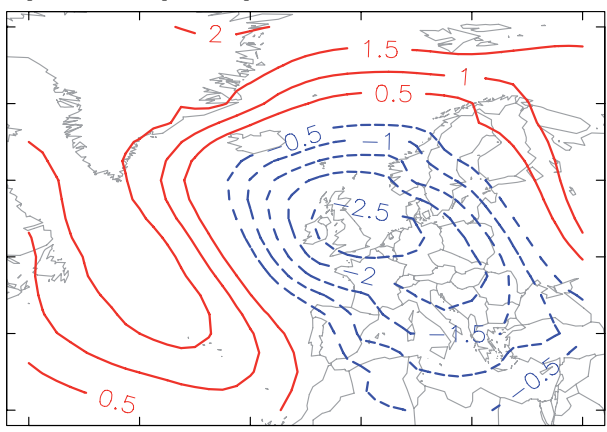

Fig. 10. Spatial loadings and percentage of total variance explained of the 3 leading DJF sea level pressure principal components over the EuroAtlantic region. (a) North Atlantic Oscillation (NAO), (b) East Atlantic pattern (EA), (c) European blocking (BLO). Shown are the sea level pressure anomalies in $\mathrm{hPa}$ associated with a principal component amplitude of $1 \mathrm{SD}$. Positive (negative) anomalies are given by solid (dashed)

lines. Contour interval is $0.5 \mathrm{hPa}$

\subsubsection{Sea level pressure pattern influences on snow pack}

To link the correlation patterns found in the previous section with well-known flow patterns, the snow pack components time series are statistically modelled with large-scale sea level pressure pattern time series as predictors using a stepwise regression approach.

The first 10 EOF sea level pressure patterns explain about $98 \%$ of the 1958-1999 DJF seasonal mean sea level pressure variance. The leading patterns (Fig. 10) show ample similarities with flow patterns in the literature (Barnston \& Livezey 1987, Pavan et al. 2000, Scherrer et al. 2006). The first PC (NAO) is virtually identical ( $\mathrm{r}>0.98)$ with a station based NAO index as defined by Hurrell (1995). The spatial and temporal components of the second component are closest to the East Atlantic pattern (EA). The third component is similar to the East Atlantic/Western Russia also called Euro-Atlantic blocking pattern (BLO).

\subsubsection{Statistical model fits}

The stepwise optimised linear model fits using 10 MSLP components as potential predictors explain about 2/3 of the NEW_SUM principal component variances (Table 3). Model diagnostics shows that the difference between observations and modelled values are mostly within \pm 1 standardised anomalies and never $>1.5$ or $<-2$. The assumption of normally distributed residuals is well satisfied. Performance is good for moderate snow years and somewhat poor for extreme years.

Of the uniform NEW_SUM pattern variance, $44 \%$ can be explained by the BLO pattern alone. This is not surprising, recalling the correlation map between the uniform NEW_SUM pattern and the sea level pressure field, which bears considerable similarity to the spatial pattern of BLO (Figs. 9a \& 10c). With exception of PC5, all other components (including the NAO) play a minor role in explaining the uniform NEW_SUM pattern. The north-south pattern variance can be mainly explained by EA, PC8 and to a rather small degree by the NAO. The correlation pattern shows large similarities with EA (cf. Figs. 9c \& 10b). Of the low-high snow pattern variance, $31 \%$ is explained by the NAO. Additionally, EA and PC4 explain larger amounts of the pattern variance.

Analogous to NEW_SUM, BLO is also the pattern explaining most of the uniform SDAY pattern variance (19\%; not shown in Table 3 ). The uniform SDAY pattern is better correlated with temperature than the leading NEW_SUM pattern (Table 2). This is also mirrored in the sea level pressure model fits for the uniform SDAY pattern (not shown). The EA pattern, which explains $41 \%$ of the leading temperature com-

Table 3. Statistical modelling of Swiss Alpine new snow sum (NEW_SUM) variability using large-scale mean sea level pressure (MSLP) PC patterns as predictors. Shown is the percentage of explained variance for the 3 leading NEW_SUM components. PCs retained in the stepwise optimised model are indicated by an asterisk. Bold: PCs explaining $>30 \%$ of variance. Numbers in parentheses are total variance explained by the full model, regular numbers by the stepwise optimised model

\begin{tabular}{|lccc|}
\hline MSLP PC & Uniform & North-south & Low-high \\
\hline NAO & $1.7^{*}$ & $6.0^{*}$ & $\mathbf{3 0 . 6}^{*}$ \\
EA & 0.0 & $\mathbf{3 4 . 3}^{*}$ & $23.6^{*}$ \\
BLO & $\mathbf{4 3 . 5}^{*}$ & 0.2 & $3.6^{*}$ \\
4 & 0.3 & $4.5^{*}$ & $10.1^{*}$ \\
5 & $16.3^{*}$ & 0.2 & 0.4 \\
6 & $5.5^{*}$ & 0.2 & 0.0 \\
7 & 0.0 & 0.5 & $1.6^{*}$ \\
8 & 1.3 & $11.7^{*}$ & $3.4^{*}$ \\
9 & 0.0 & $4.9^{*}$ & 0.0 \\
10 & 0.5 & $2.1^{*}$ & 0.0 \\
Total & $67.0(69.1)$ & $63.5(64.6)$ & $72.9(73.3)$ \\
\hline
\end{tabular}


ponent variance, is the second most important pattern explaining $14 \%$ of the uniform SDAY pattern total variance (not shown).

Another reasonable approach to compare the similarities between the correlation patterns of Fig. 9 and the flow patterns of Fig. 10 is to compute spatial correlation coefficients between the correlation maps and spatial loadings of the leading pressure patterns. The absolute values of the spatial correlation coefficients $\left(\mathrm{r}_{\mathrm{sp}}\right)$ are large and highly significant for the MSLP PCs that explain large amounts of the snow pattern variance $\left(\mid \mathrm{r}_{\mathrm{sp}}(\right.$ unif-BLO$)|=0.79,| \mathrm{r}_{\mathrm{sp}}$ (north-south-EA) $\mid=$ $0.65, \mid \mathrm{r}_{\mathrm{sp}}($ low-high-NAO) $\mid=0.84)$. Small values are found for the MSLP PCs explaining small amounts of the snow pattern variance. The results agree with the model fits (cf. Table 3).

\section{CONCLUSIONS}

In this study we used quality checked Swiss Alpine snow data (new snow sums, average snow depths and snow days) to: (1) determine and discuss the major patterns of observed seasonal mean snow variability; (2) investigate the link between seasonal mean winter (DJF) snow patterns and local temperature and precipitation variability; (3) work out the influence of largescale flow patterns on snow variability and trends. The main results are summarised in Table 4.

For new snow sums and snow depths 3 well separated patterns of variability were identified. The first (uniform) pattern explains $>50 \%$ of total variance and the spatial pattern is almost uniform over the entire Swiss area with exception of the southern Alps, where the loading is small. The second (north-south) pattern (explaining $\sim 15 \%$ of total variance) shows a northsouth dipole with positive (negative) loadings on the northern (southern) slopes of the Alps. The third (lowhigh) pattern (explaining $~ 9 \%$ of total variance) shows positive loadings at low altitude stations, negative loadings at high altitude stations and a weak, decreasing trend.
The snow patterns are highly correlated with local temperature and precipitation. However, the correlation strongly depends on the snow variable considered. New snow sum anomalies of the leading pattern are primarily related to seasonal precipitation anomalies. Snow day sum leading pattern anomalies on the other hand are primarily related to seasonal temperature anomalies and only weakly to precipitation anomalies, as melt processes are almost linearly related to seasonal temperature (e.g. Ohmura 2001). The change from precipitation dominance for new snow sums to temperature dominance for snow days can be explained by the different character of the variables: new snow sums are only influenced by processes during snow accumulation (i.e. during snowfall events). Evidently these can be described reasonably by seasonal precipitation sums. On the other hand, the leading snow day variability is influenced by processes that control snow accumulation and ablation, which are highly related to seasonal temperature. The northsouth snow pattern, which explains most of snow variability in southern Switzerland, correlates excellently with southern Alpine precipitation. The low-high snow pattern correlates with well local temperature.

Also the large-scale flow explains substantial amounts of variance in the Swiss Alpine snow pattern data. The leading pattern of snow variability is primarily linked with a low (high) pressure anomaly pattern centred over central and southeastern Europe. It bears some resemblance to the third pattern of European sea level pressure variability (BLO) often referred to as Euro-Atlantic blocking (D'Andrea et al. 1998, Scherrer et al. 2006). Similarities also exist with the mid-latitude anomaly train pattern (Massacand \& Davies 2001), the sea level patterns associated with the leading Swiss Alpine winter precipitation variability (Widmann 1996), the leading European winter precipitation variability pattern (Qian et al. 2000), the second canonical pattern in extreme winter wet days (Haylock \& Goodess 2004) and the pattern connected to the second EOF of European and northern African winter precipitation (Rodriguez-Fonseca et al. 2006). The second (north-

Table 4. Properties of the 3 leading patterns of Swiss Alpine new snow sum (NEW_SUM), snow depth (SDEPTH) and snow day (SDAY) variability. Shown are mean fraction of explained variance, primary influence region and trend information. The other columns show the primary influences of local climate (temperature and precipitation) and large-scale flow (mean sea surface pressure variability) on these patterns. Precip: precipitation; temp: temperature; ewh: everywhere except southernmost parts; sAlps: Southern Alpine slopes; low-sAlps: low stations, especially in the south; BLO: Blocking pattern; EA: Eastern Atlantic pattern; NAO: North Atlantic Oscillation (see text for definitions)

\begin{tabular}{|c|c|c|c|c|c|c|c|}
\hline & \multicolumn{3}{|c|}{ Snow pattern } & \multicolumn{3}{|c|}{ Local climate } & \multirow{2}{*}{$\begin{array}{c}\text { Large-scale flow } \\
\text { NEW_SUM/SDEPTH/SDAY }\end{array}$} \\
\hline & Variance (\%) & Influence & Trend & NEW_SUM & 1 SDEPTH & SDAY & \\
\hline Uniform & $\sim 50$ & ewh & None & Precip & Precip \& temp & Temp & BLO \\
\hline North-south & $\sim 15$ & sAlps & None & Precip & Precip & Precip & EA \\
\hline Low-high & $\sim 9$ & low-sAlps & Negative & Temp & Temp & Temp & NAO \\
\hline
\end{tabular}


south) snow pattern is mainly influenced by the East Atlantic anomaly pattern. Only the low-high snow pattern variability, which explains substantial amounts of interannual snow variance at low-lying stations, is primarily linked with the interannual variability of the NAO. We find several indications that this low-high pattern could be related to ongoing climate change. It shows no similarity with known precipitation patterns, is strongly linked with the increase of the $0^{\circ} \mathrm{C}$ isotherm, exhibits a negative trend, and its correlation with NAO decreases from near zero to a highly significant negative value towards the end of the 20th century.

Acknowledgements. This study was supported by the Swiss NSF through the National Centre for Competence in Research Climate (NCCR-Climate). The snow dataset used is courtesy of M. Laternser from SLF Davos. The constructive comments of C. Schär and 4 anonymous reviewers are gratefully acknowledged.

\section{LITERATURE CITED}

Abegg B (1996) Klimaänderung und Tourismus: Klimafolgenforschung am Beispiel des Wintertourismus in den Schweizer Alpen. vdf, Hochschulverlag AG an der ETH Zürich, Zürich

Appenzeller C, Weiss AK, Staehelin J (2000) North Atlantic Oscillation modulates total ozone winter trends. Geophys Res Lett 27:1131-1134

Appenzeller C, Stocker TF, Schmittner A (2001) Natural climate variability and climate change in the North-Atlantic European sector: chance for surprise? Integr Assess 1: 301-306

Baeriswyl PA, Rebetez M (1997) Regionalization of precipitation in Switzerland by means of principal component analysis. Theor Appl Climatol 58:31-41

Barnston AG, Livezey RE (1987) Classification, seasonality and persistence of low-frequency atmospheric circulation patterns. Mon Weather Rev 115:1083-1126

Beckers JM, Rixen M (2003) EOF calculations and data filling from incomplete oceanographic datasets. J Atmos Ocean Technol 20:1839-1856

Bednorz E (2002) Snow cover in western Poland and macroscale circulation conditions. Int J Climatol 22:533-541

Begert M, Schlegel T, Kirchhofer W (2005) Homogeneous temperature and precipitation series of Switzerland from 1864 to 2000. Int J Climatol 25:65-80

Beniston M (1997) Variations of snow depth and duration in the Swiss Alps over the last 50 years: links to changes in large-scale climatic forcings. Clim Change 36:281-300

Beniston M, Keller F, Goyette S (2003) Snow pack in the Swiss Alps under changing climatic conditions: an empirical approach for climate impacts studies. Theor Appl Climatol 74:19-31

Cayan DR (1996) Interannual climate variability and snowpack in the western United States. J Clim 9:928-948

Clark MP, Serreze MC, Robinson DA (1999) Atmospheric controls on Eurasian snow extent. Int J Climatol 19:27-40

D'Andrea F, Tibaldi S, Blackburn M, Boer G and 13 others (1998) Northern Hemisphere atmospheric blocking as simulated by 15 atmospheric general circulation models in the period 1979-1988. Clim Dyn 14:385-407
Dettinger MD, Cayan DR (1995) Large-Scale Atmospheric Forcing of Recent Trends toward Early Snowmelt Runoff in California. J Clim 8:606-623

Elsasser H, Messerli P (2001) The vulnerability of the snow industry in the Swiss Alps. Mt Res Dev 21:335-339

Frei A, Robinson DA (1999) Northern hemisphere snow extent: regional variability 1972-1994. Int J Climatol 19: $1535-1560$

Gutzler DF, Rosen RD (1992) Interannual variability of wintertime snow cover across the Northern Hemisphere. J Clim 5:1441-1447

Gyalistras D, Rohrer MB, Wahrenberger C, Lorenzi D, Schwarb M (2005) Assessing the sensitivity of local snow cover to global climate change: a general method and its application to five Swiss locations. Unpublished report; available at: http://climate-impacts.ch/_DGGrey/Gyal_05_ SnowCoverSensi.pdf

Hantel M, Ehrendorfer M, Haslinger A (2000) Climate sensitivity of snow cover duration in Austria. Int $\mathrm{J}$ Climatol 20:615-640

Haylock MR, Goodess CM (2004) Interannual variability of European extreme winter rainfall and links with mean large-scale circulation. Int J Climatol 24:759-776

Hurrell JW (1995) Decadal trends in the North Atlantic Oscillation regional temperatures and precipitation. Science 269:676-679

Junge MM, Stephenson DB (2003) Mediated and direct effects of the North Atlantic Ocean on winter temperatures in northwest Europe. Int J Climatol 23:245-261

Laternser M, Schneebeli M (2003) Long-term snow climate trends of the Swiss Alps (1931-99). Int J Climatol 23:733-750

Laternser MC (2002) Snow and avalanche climatology of Switzerland. PhD thesis no. 14493, Eidgenössisch Technische Hochschule (ETH), Zürich

Massacand AC, Davies HC (2001) Interannual variability of European winter weather: the potential vorticity insight. Atmos Sci Lett 2:52-60

McCabe GJ, Dettinger MD (2002) Primary modes and predictability of year-to-year snowpack variations in the western United States from teleconnections with Pacific Ocean climate. J Hydrometeorol 3:13-25

North GR, Bell TL, Cahalan RF, Moeng FJ (1982) Sampling errors in the estimation of empirical orthogonal functions. Mon Weather Rev 110:699-706

Ohmura A (2001) Physical basis for the temperature-based melt-index method. J Appl Meteorol 40:753-761

Pavan V, Molteni F, Brankovic C (2000) Wintertime variability in the Euro-Atlantic region in observations and in ECMWF seasonal ensemble experiments. Q J R Meteorol Soc 126:2143-2173

Preisendorfer RW (1988) Principle component analysis in meteorology and oceanography, Vol 17. Elsevier, Amsterdam

Qian BD, Corte-Real J, Xu H (2000) Is the North Atlantic Oscillation the most important atmospheric pattern for precipitation in Europe? J Geophys Res Atmos 105: 11901-11910

Rodriguez-Fonseca B, Polo I, Serrano E, Castro M (2006) Evaluation of the North Atlantic SST forcing on the European and northern African winter climate. Int J Climatol 26:179-191, doi: 10.1002/joc.1234

Schär C, Davies TD, Frei C, Wanner H, Widmann M, Wild M, Davies HC (1998) Current alpine climate. In: Cebon P, Dahinden U, Davies HC, Imboden D, Jaeger CC (eds) Views from the Alps. Regional perspectives on climate change. MIT Press, Cambridge, MA, p 21-72 
Scherrer SC, Appenzeller C, Laternser MC (2004) Trends in Swiss Alpine snow days - the role of local- and largescale climate variability. Geophys Res Lett 31:L13215, doi:10.1029/2004GL020255

Scherrer SC, Croci-Maspoli M, Schwierz C, Appenzeller C (2006) Two dimensional indices of atmospheric blocking and their statistical relationship with winter climate patterns in the Euro-Atlantic region. Int $\mathrm{J}$ Climatol 26: 233-249, doi:10.1002/joc.1250

Schmidli J, Schmutz C, Frei C, Wanner H, Schär C (2002) Mesoscale precipitation variability in the region of the European Alps during the 20th century. Int J Climatol 22: 1049-1074

Editorial responsibility: Eric DeWeaver,

Madison, Wisconsin, USA
Uppala SM, Kallberg PW, Simmons AJ, Andrae U and 7 others (2005) The ERA-40 reanalysis. Q J R Meteorol Soc 131: $2961-3012$

Wanner H, Gyalistras D, Luterbacher J, Rickli R, Salvisberg E, Schmutz C (2000) Klimawandel im Schweizer Alpenraum. vdf Hochschulverlag AG an der ETH Zürich, Zürich

Widmann M (1996) Mesoscale variability and long-term trends of Alpine precipitation and their relation to the synoptic scale flow. PhD thesis no. 11769, Eidgenössisch Technische Hochschule (ETH), Zürich

Widmann M, Schär C (1997) A principal component and longterm trend analysis of daily precipitation in Switzerland. Int J Climatol 17:1333-1356

Submitted: January 30, 2006; Accepted: August 10, 2006 Proofs received from author(s): October 21, 2006 